\title{
Docência e ensino profissional no Brasil e em Portugal ${ }^{1}$
}

\section{Teaching in technical education in Brazil and Portugal}

\author{
Cristhianny Bento Barreiro* \\ Maria João Mogarro**
}

\begin{abstract}
RESUMO
Este trabalho apresenta estudo comparado sobre a organização da educação profissional de nível médio no Brasil e em Portugal. O objetivo foi o de compreender como se organizam e se estruturam os cursos profissionais no âmbito da educação formal, bem como descrever os requisitos de acesso à docência, especificamente nas componentes curriculares profissionalizantes. Trata-se de uma pesquisa qualitativa, cujo córpus constituiu-se de legislações, bem como de publicações oriundas de pesquisa em bases de dados com o tema formação de professores para educação profissional no Brasil e em Portugal. Como resultados, pode-se afirmar que a formação de professores para a Educação Profissional não está instituída na prática das instituições em nenhum dos dois países, tendo amparo legal em Portugal e um recuo na valorização do pedagógico no Brasil.

Palavras-chave: Ensino Técnico. Formação de Professores. Brasil. Portugal.
\end{abstract}

\begin{abstract}
This paper presents a comparative study on the organization of professional secondary education in Brazil and Portugal. The objective was to understand how professional courses are organized and structured in the scope of formal
\end{abstract}

1 Projeto de investigação financiado pelo Programa de Pós-doutorado da Coordenação de Aperfeiçoamento de Pessoal de Nível Superior (CAPES). Edital n. 15/2016, processo n. $88881.120341 / 2016-01$.

* Instituto Federal de Educação, Ciência e Tecnologia Sul-Rio-Grandense. Pelotas, Rio Grande do Sul, Brasil. E-mail: crisbarreiro@pelotas.ifsul.edu.br - https://orcid.org/0000-0001-7547-1905

${ }^{* *}$ Universidade de Lisboa. Lisboa, Portugal. E-mail: mjmogarro@ie.ulisboa.pt - https:// orcid.org/0000-0002-5841-9280 
education, as well as to describe the requirements of access to teaching, specifically in the vocational curricular components. This qualitative research, whose corpus consisted of legislations, as well as publications from database research on teacher education for professional education in Brazil and Portugal. As a result, it can be affirmed that teacher training for Vocational Education is not instituted in the practice of institutions in either country, with legal support in Portugal and a decline in the valorization of pedagogical in Brazil.

Keywords: Technical Education. Teaching Training. Brazil. Portugal.

\section{Introdução}

O mundo atual, o mundo da educação, obriga-nos a cultivar com uma mão o ceticismo e com a outra, a utopia. O ceticismo que nos vem da consciência de saber que a educação é sempre um dos espaços sociais nos quais se produz a desigualdade e a discriminação frente aos outros:

o outro-pobre, o outro-negro, o outro-mulher, o outro-estrangeiro. É preciso estar atento. A utopia que nos vem da consciência de saber que tudo é ainda possível, que existe uma ciência a reinventar e que esta ciência não será asséptica, indiferente, cega à vida.

António Nóvoa

Recentemente o Brasil passou por uma mudança em sua Lei de Diretrizes e Bases da Educação Nacional (LDBEN), para que o Ensino Médio fosse modificado. Estas modificações justificaram-se com base em estatísticas que assinalam que as matrículas do ensino médio caíram de 8,7 milhões para 8,3 milhões na última década (2002-2012), que pouco mais de 50\% dos jovens entre 15 e 18 anos frequentam o Ensino Médio (Pesquisa Nacional de Amostras por Domicílio - PNAD) e em um estudo realizado pelo Centro Brasileiro de Análise e Planejamento (CEBRAP), com apoio da Fundação Víctor Civita, que concluiu que há falta de interesse dos jovens em cursar esta etapa da educação básica (TORRES, 2013), em que pese os interesses econômicos e sociais que podem estar envolvidos em tal estudo, patrocinado pelo Banco Itaú e pela Fundação Telefônica Vivo.

O discurso pela melhoria da qualidade da educação tem estado no centro do debate. Os números, estatísticas, pesquisas, de diversas ordens e natureza, invadem as mídias e provocam discussões sobre a temática. Usam-se modelos 
de ensino de outros países para justificar alterações realizadas. Vivemos em um mundo globalizado, em que as políticas de um país acabam por influenciar nos rumos da política de outros países, especialmente seguindo a lógica colonialista em que os modelos do norte são importados para o sul.

Desta maneira, este artigo apresenta um estudo comparado entre Brasil e Portugal, neste momento de implantação de mudança do Ensino Médio, que modifica por extensão a Educação Profissional. A partir das questões: como se organiza o ensino profissional em etapa correspondente ao nível médio/ secundário no Brasil e em Portugal e quais os requisitos para exercer a docência nas disciplinas técnicas desta etapa de ensino? O estudo teve por objetivo compreender como se organizam e se estruturam os cursos profissionais no âmbito da educação formal, bem como descrever os requisitos de acesso à docência, especificamente nas componentes curriculares profissionalizantes.

Primeiramente será apresentada a metodologia do estudo. A seguir, a organização do Ensino Médio em Portugal e no Brasil, focando especificamente na Educação Técnica. Logo após, apresenta-se a questão dos requisitos legais para acesso a carreira de professores nesta modalidade de educação. Finalizando com algumas conclusões sobre a temática.

\section{Metodologia}

O estudo aqui apresentado encontra-se no âmbito das pesquisas qualitativas em educação e desta forma busca compreender os fenômenos em seus contextos (BOGDAN; BIKLEN, 1994). A questão que mobilizou esta investigação foi: "Como se organiza o ensino profissional em etapa correspondente ao nível médio/secundário no Brasil e em Portugal e quais os requisitos para exercer a docência nas disciplinas técnicas desta etapa de ensino?" O método utilizado foi a análise documental. Integraram o córpus de análise as Leis de Bases do Sistema Educativo de Portugal, a Lei de Diretrizes e Bases da Educação Nacional do Brasil, além de artigos, livros e cadernos encontrados em buscas realizadas nas bases de dados como Scielo, na biblioteca da Universidade de Lisboa e, também, através do Google, com o descritor "Educação Profissional Brasil Portugal". Os trabalhos que se relacionavam com a questão proposta foram separados, lidos e analisados. Os objetivos foram: descrever como se situa o ensino técnico em ambos os países, relacionar este ensino ao ensino médio ou secundário e compreender sua estruturação. Além disso, evidenciar os requisitos legais de acesso ao exercício da docência, especificamente no que se relaciona às disciplinas técnicas deste nível de ensino. 
Trata-se, portanto, de um estudo comparado, assumindo a perspectiva de que: "A pesquisa comparativa interpreta e constrói fatos, não se limitando a descobri-los ou descrevê-los" (NÓVOA, 2010, p. 52).

Apesar da crítica que estudos comparados que envolvam Norte-Sul possam receber, o estudo busca comparar a estruturação da docência na Educação Profissional nestes países, já que os discursos que envolvem as reformas brasileiras manifestam a inspiração nesta perspectiva, de importar "modelos" do Norte para o hemisfério Sul do mundo. A escassez de trabalhos acadêmicos nas buscas demonstra que o tema é bastante ainda inexplorado, o que anuncia o possível potencial da investigação. Sobretudo a Reforma do Ensino Médio, implantada pela Lei ${ }^{\circ} 13.415$ de fevereiro de 2017 (BRASIL, 2017a), parece ter forte inspiração no Sistema Educativo de outros países, o que ficará evidenciado na próxima seção.

\section{Organização do ensino médio no Brasil e em Portugal}

No âmbito do sistema educativo português, a educação escolar compreende os ensinos básico, secundário e superior, integra modalidades especiais e inclui atividades de ocupação de tempos livres, conforme a Lei de Bases do Sistema Educativo (LBSE) em seu Art.4 (PORTUGAL, 2005). O ensino básico é composto de 3 ciclos, num total de 9 anos de escolarização. O ensino secundário organiza-se em cursos predominantemente orientados para a vida ativa e cursos predominantemente orientados para o prosseguimento de estudos, perfazendo um total de 3 anos.

\section{FIGURA 1 - SISTEMA EDUCATIVO PORTUGUÊS}

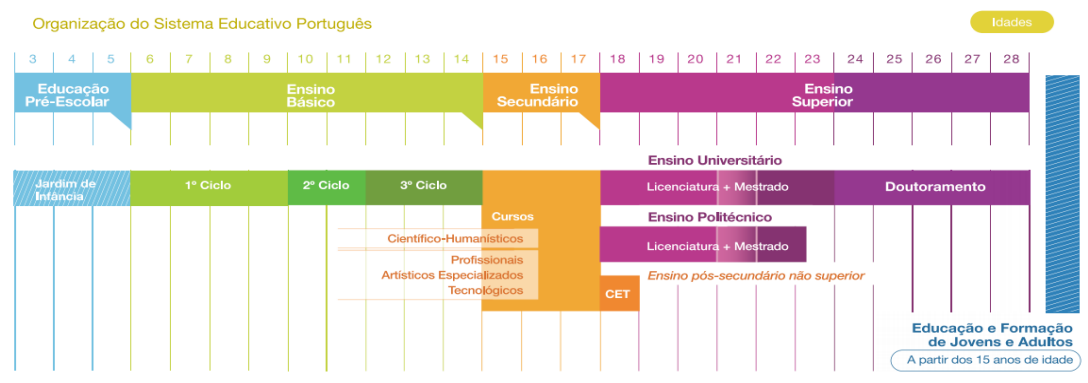

FONTE: Educação em números (PORTUGAL, 2008). 
São objetivos do ensino secundário, conforme o Art. 9 da LBSE:

a) Assegurar o desenvolvimento do raciocínio, da reflexão e da curiosidade científica e o aprofundamento dos elementos fundamentais de uma cultura humanística, artística, científica e técnica que constituam suporte cognitivo e metodológico apropriado para o eventual prosseguimento de estudos e para a inserção na vida ativa; [...]

e) Facultar contatos e experiências com o mundo do trabalho, fortalecendo os mecanismos de aproximação entre a escola, a vida ativa e a comunidade e dinamizando a função inovadora e interventora da escola;

f) Favorecer a orientação e formação profissional dos jovens, através da preparação técnica e tecnológica, com vista à entrada no mundo do trabalho; [...] (PORTUGAL, 2005).

Os cursos secundários orientados ao prosseguimento de estudos, chamamse de Cursos Científico-Humanísticos e subdividem-se em Curso de Ciências e Tecnologias; Curso de Ciências Socioeconómicas; Curso de Línguas e Humanidades; Curso de Artes Visuais. Assim, estes cursos possuem componentes de formação geral: Português, Língua Estrangeira, Filosofia e Educação Física, comum a todos, e componentes de formação específica, pertencentes ao curso escolhido pelo estudante. O gráfico a seguir mostra a distribuição de estudantes de acordo com o curso escolhido, totalizando 204.105 matriculados no ano de 2015.

\section{FIGURA 2 - GRÁFICO DE DISTRIBUIÇÃO DOS ESTUDANTES}

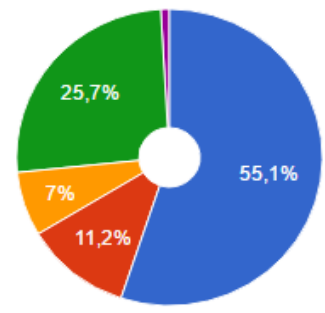

Ciências e Tecnologias

Ciências SocioEconómicas

Artes Visuais

Linguas e Humanidades

Outros / não identificados

FONTE: Estátisticas do Ensino Secundário. (PORTUGAL, 2015). 
É no âmbito do ensino secundário orientado para a vida ativa que aparecem os Cursos Profissionais e os Cursos Tecnológicos, destinados aos estudantes que concluíram os 9 anos de ensino básico, procuram um ensino mais voltado ao mundo do trabalho sem, no entanto, deixar de lado a possibilidade de prosseguirem seus estudos. Os Cursos Tecnológicos desenvolvem-se no âmbito das escolas secundárias, enquanto os Cursos Profissionais acontecem em escolas secundárias e, também, em escolas específicas criadas por demandas comunitárias, de organizações ou de outros sistemas, que busquem suprir determinada necessidade de formação e mantém o seu financiamento.

Os Cursos Tecnológicos e os Cursos Profissionais, alvo do estudo, são àqueles ofertados pelas Escolas Secundárias, já que se encontram em estreita convivência com o ensino secundário e, assim, a comparação da investigação acontecerá entre estes cursos e os chamados Cursos Integrados, no Brasil, que integram ensino médio e ensino profissional.

Abaixo, apresenta-se a grade curricular para os Cursos Profissionais:

FIGURA 3 - GRADE CURRICULAR CURSOS PROFISSIONAIS

\begin{tabular}{|l|l|l|}
\hline $\begin{array}{l}\text { COMPONENTES } \\
\text { DE FORMAÇÃO }\end{array}$ & DISCIPLINAS & $\begin{array}{l}\text { TOTAL DE } \\
\text { HORAS }\end{array}$ \\
\hline \multirow{4}{*}{ Sociocultural } & Português & $320 \mathrm{~h}$ \\
\cline { 2 - 3 } & Língua Estrangeira & $220 \mathrm{~h}$ \\
\cline { 2 - 3 } & Tecnologias da Informação e Comunicação & $100 \mathrm{~h}$ \\
\cline { 2 - 3 } & Educação Física & $140 \mathrm{~h}$ \\
\hline Científica & 2 a 3 disciplinas & $500 \mathrm{~h}$ \\
\hline \multirow{2}{*}{ Técnica } & 3 a 4 disciplinas & $1180 \mathrm{~h}$ \\
\cline { 2 - 3 } & Formação em Contexto de Trabalho & $420 \mathrm{~h}$ \\
\hline Carga horária total/ Curso & $3100 \mathrm{~h}$ \\
\hline
\end{tabular}

FONTE: Agência Nacional para a Qualificação e Ensino Profissional (PORTUGAL, 2017).

Estes cursos são regulados pela Agência Nacional para a Qualificação e o Ensino Profissional (ANQEP)², agrupam-se em famílias, listadas a seguir, às quais estão relacionados os diversos cursos técnicos:

2 A Agência Nacional para a Qualificação e o Ensino Profissional, I. P. (ANQEP, I. P.) é um instituto público integrado na administração indireta do Estado, com autonomia administrativa, financeira e pedagógica no prosseguimento das suas atribuições, sob a superintendência e tutela conjunta dos Ministérios da Educação, e do Trabalho, Solidariedade e Segurança Social, em coordenação com o Ministério da Economia. 
FIGURA 4 - QUADRO DE FAMÍLIAS DOS CURSOS PROFISSIONAIS

\begin{tabular}{|l|}
\hline Artes do espetáculo \\
\hline Audiovisuais e produção dos media \\
\hline Design \\
\hline Artesanato \\
\hline Filosofia, história e ciências afins \\
\hline Jornalismo \\
\hline Biblioteconomia, arquivo e documentação (BAD) \\
\hline Comércio \\
\hline Marketing e publicidade \\
\hline Finanças, banca e seguros \\
\hline Contabilidade e fiscalidade \\
\hline Gestão e administração \\
\hline Secretariado e trabalho administrativo \\
\hline Enquadramento na organização/empresa \\
\hline Ciências informáticas \\
\hline Metalurgia e metalomecânica \\
\hline Eletricidade e energia \\
\hline Eletrónica e automação \\
\hline Engenharia química \\
\hline Construção e reparação de veículos a motor \\
\hline Indústrias alimentares \\
\hline Têxtil, vestuário, calçado e couros \\
\hline Materiais (madeira, papel, plástico, vidro e outros) \\
\hline Indústrias extrativas \\
\hline Arquitetura e urbanismo \\
\hline Construção civil \\
\hline Produção agrícola e animal \\
\hline Floricultura e jardinagem \\
\hline Silvicultura e caça \\
\hline Pescas \\
\hline Serviços de saúde \\
\hline Ciências dentárias \\
\hline Serviços de apoio a crianças e jovens \\
\hline Trabalho social e orientação \\
\hline Hotelaria e restauração \\
\hline Turismo e lazer \\
\hline Proteção do ambiente \\
\hline Proteção de pessoas e bens \\
\hline Segurança e higiene no trabalho \\
\hline
\end{tabular}

FONTE: Agência Nacional para a Qualificação e Ensino Profissional (PORTUGAL, 2017). 
A importância atribuída ao Ensino Profissional em Portugal pode ser verificada na Circular n. 1/ANQEP/2017 (PORTUGAL, 2017). Nela é informado o propósito de que, até $2020,50 \%$ dos alunos que frequentam o ensino secundário realizem percursos de dupla certificação, secundária e profissional. No ano de 2018, em torno de 115 mil estudantes frequentavam os Cursos Profissionais e Tecnológicos, o que representava $29 \%$ do total neste nível de ensino (PORTUGAL, 2018).

No âmbito do sistema educativo brasileiro, a educação escolar abrange a educação básica, formada pela educação infantil, ensino fundamental e ensino médio, e a educação superior, formada por graduação e pós-graduação. A educação infantil é oferecida em creches até os 3 anos de idade e em préescolas, dos 4 aos 5 anos. O ensino fundamental possui um total de 9 anos de escolarização e o ensino médio tem uma duração mínima de 3 anos. Esta última etapa da chamada educação básica sofreu recentes e controversas modificações. Tais medidas estão sendo implantadas e deixam diversas incertezas sobre o currículo do ensino médio no Brasil, ao remeterem ao que chamam de Base Nacional Comum Curricular, documento de referência que tem estabelecido mais dúvidas do que caminhos possíveis, já que promoveu o esvaziamento disciplinar (BRASIL, 2018).

FIGURA 5 - ORGANIZAÇÃO DO SISTEMA EDUCATIVO BRASILEIRO

\begin{tabular}{|c|c|c|c|c|}
\hline \multicolumn{3}{|c|}{ Educação Básica } & \multicolumn{2}{|c|}{ Ensino Superior } \\
\hline $\begin{array}{c}\text { Educação } \\
\text { Infantil }\end{array}$ & $\begin{array}{c}\text { Ensino } \\
\text { Fundamental }\end{array}$ & $\begin{array}{l}\text { Ensino } \\
\text { Médio }\end{array}$ & $\begin{array}{c}\text { Ensino de } \\
\text { Graduação }\end{array}$ & $\begin{array}{c}\text { Ensino de } \\
\text { Pós-graduação }\end{array}$ \\
\hline
\end{tabular}

\begin{tabular}{ccccccc|}
$\begin{array}{c}0 \text { aos } 3 \\
\text { anos }\end{array}$ & $\begin{array}{c}4 \text { e } 5 \\
\text { anos }\end{array}$ & $\begin{array}{c}\text { 6 aos } 14 \\
\text { anos }\end{array}$ & $\begin{array}{c}15 \text { aos } 18 \\
\text { anos }\end{array}$ & $\begin{array}{c}19 \text { aos } 23 \\
\text { anos }\end{array}$ & $\begin{array}{c}24 \text { e } 25 \\
\text { anos }\end{array}$ & $\begin{array}{c}26 \text { aos } 30 \\
\text { anos }\end{array}$ \\
\hline Berçário & $\begin{array}{c}\text { Jardim e } \\
\text { Pré }\end{array}$ & $1^{\circ}$ ao $9^{\circ}$ ano & $1^{\circ}$ ao $3^{\circ} / 4^{\circ}$ ano & $\begin{array}{c}1^{\circ} \text { ao } 4^{\circ} / 5^{\circ} \\
\text { ano }\end{array}$ & Mestrado & Doutorado \\
\hline
\end{tabular}

\author{
Educação de \\ Jovens e Adultos \\ A partir de 15 anos
}

FONTE: as autoras.

O ensino médio poderá ter os seguintes itinerários formativos: Linguagens e suas tecnologias, Matemática e suas tecnologias, Ciências da natureza e suas tecnologias, Ciências humanas e sociais aplicadas e Formação técnica e profissional. 
Neste momento, é difícil visualizar o currículo do novo ensino médio, já que a Base Nacional Comum Curricular na Etapa do Ensino Médio - BNCC$\mathrm{EM}$, disponibilizada através da Resolução $\mathrm{CNE} / \mathrm{CP} \mathrm{n}^{\circ} 4$ de 17 de dezembro de 2018, estabelece competências nas quais o domínio das áreas disciplinares parecem incertas. Sabe-se que Português e Matemática estarão presentes nos 3 anos de formação, que Língua Inglesa será obrigatória, assim como práticas de Educação Física, Arte, Sociologia e Filosofia. Também é possível saber que a BNCC estabelece um máximo de 1800 horas e que às demais horas deverão corresponder à especialização do itinerário formativo escolhido (BRASIL, 1996, 2018).

Os Cursos Técnicos Profissionais de nível médio poderão ocorrer de forma articulada ao ensino médio, podendo ser integrado ou concomitante, ou de forma subsequente, quando o estudante já terminou esta etapa de ensino. $\mathrm{O}$ ensino concomitante acontece em dois períodos diários, o estudante possui uma matrícula referente ao ensino médio e outra referente ao ensino técnico, podendo ser em uma mesma escola ou em escolas diferenciadas. O Ensino Médio Integrado busca a integração dos conhecimentos científicos-humanísticosartísticos e técnicos em sua matriz, habilitando o estudante para a entrada no mundo do trabalho e para o prosseguimento de estudos.

Atualmente, o Brasil conta com 8,1 milhões de estudantes no ensino médio, dos quais 1,9 milhões estão na educação profissional, o que corresponde a $23,5 \%$ e, deste total, em torno de 500 mil estudantes frequentam o Ensino Médio Integrado (BRASIL, 2017b).

$\mathrm{Na}$ União Europeia, a taxa de conclusão dos jovens da etapa de ensino correspondente ao ensino médio estava na ordem dos $79 \%$, enquanto que no Brasil esta taxa estava na ordem dos 37\%, no ano de 2013. O Ensino Médio Integrado parecia ser uma aposta para que se superasse o desinteresse dos jovens nesta etapa da educação (PEREIRA; TEIXEIRA, 2014). Porém, com a recente mudança de rumos políticos no Brasil, este cenário alterou-se e a aposta para que isso seja sanado parece ser a flexibilização dos currículos em itinerários formativos diferenciados, em implantação. Ainda assim, o Ensino Médio Integrado continua existindo, sendo a principal aposta da Rede Federal de Educação Profissional e Tecnológica para a superação do suposto desinteresse dos jovens.

Os cursos estão agrupados em áreas, listadas no Catálogo Nacional de Cursos, que podem ser observadas a seguir: 
FIGURA 6 - CATÁLOGO NACIONAL DE CURSOS

\begin{tabular}{|c|}
\hline Ambiente e Saúde \\
\hline Controle e Processos Industriais \\
\hline Desenvolvimento Educacional e Social \\
\hline Gestão e Negócios \\
\hline Informação e comunicação \\
\hline Infraestrutura \\
\hline Militar \\
\hline Produção alimentícia \\
\hline Produção Cultural e Design \\
\hline Produção Industrial \\
\hline Recursos Naturais \\
\hline Segurança \\
\hline Turismo, Hospitalidade e Lazer \\
\hline
\end{tabular}

FONTE: Catálogo Nacional de Cursos Técnicos (BRASIL, 2016).

Pode-se perceber que a ideia de escolha de diferentes formações no ensino secundário está presente em ambos os países. No entanto, percentualmente, em Portugal há um número superior de matriculados nos Cursos Profissionais com a perspectiva de que estas matrículas atinjam $50 \%$ do total de matriculados. O Brasil vinha fazendo forte investimento na Educação Profissional, no entanto, com a mudança de rumos do governo e instabilidade política, torna-se difícil prever qual será o direcionamento da educação de nível médio.

A seguir, uma breve descrição dos requisitos para ingresso para o exercício da docência nas componentes curriculares profissionalizantes da Educação Profissional.

\section{Formação docente: requisitos em debate}

A primeira questão que precisa ser pontuada aqui é a identidade do professor da Educação Profissional. Há diversas áreas nas quais não há mais esta dúvida: o professor de matemática é o licenciado ${ }^{3}$ em matemática, o professor de geografia é o licenciado em geografia. Mas quem é o professor responsável por ensinar eletrônica, mecânica, construção civil, direito ou administração em um curso técnico?

3 Licenciado aqui designa àquele que concluiu uma graduação que habilita para o exercício da docência, conforme sentido atribuído no Brasil. Em Portugal, o termo licenciado é utilizado para designar aquele que conclui um curso de ensino superior. 
A Educação Profissional, enquanto parte do ensino secundário ou médio, fica submetida aos seus regramentos. Em Portugal, a Lei de Bases do Sistema Educativo anuncia que:

1 - Os educadores de infância e os professores dos ensinos básico e secundário adquirem a qualificação profissional através de cursos superiores organizados de acordo com as necessidades do desempenho profissional no respectivo nível de educação e ensino. [...]

6 - A qualificação profissional dos professores de disciplinas de natureza profissional, vocacional ou artística dos ensinos básico ou secundário pode adquirir-se através de cursos de licenciatura que assegurem a formação na área da disciplina respectiva, complementados por formação pedagógica adequada.

7 - A qualificação profissional dos professores do ensino secundário pode ainda adquirir-se através de cursos de licenciatura que assegurem a formação científica na área de docência respectiva, complementados por formação pedagógica adequada (Art. 34) (PORTUGAL, 2005).

O cenário de requisitos de formação de professores tem dois momentos distintos, anterior ao Processo de Bolonha e Pós-Bolonha:

No que à situação portuguesa diz respeito, desde a publicação da primeira Lei de Bases do Sistema Educativo (Lei n ${ }^{\circ} 46 / 86$, de 14 de outubro), podem ser identificados, pelo menos, dois momentos em que ocorreram alterações nas políticas de formação de professores: um primeiro, no final da década de noventa, no qual foi implementada uma política de atribuição de grau de licenciatura a todos os educadores/professores, independentemente do nível de ensino em que exerciam a sua profissão; um segundo momento, associado à adequação ao Processo de Bolonha (2006) decorrente da assinatura da Declaração de Bolonha (1999) e que teve como efeito que a formação de professores dos $2^{\circ}$ e $3^{\circ}$ ciclos do ensino básico e dos professores do ensino secundário ocorresse apenas durante o $2^{\circ}$ ciclo da formação do ensino superior (MOURAZ; LEITE; FERNANDES, 2012, p. 190).

Desta forma, "a legislação recentemente promulgada exige que a formação profissional de professores, de todos os níveis de ensino não superior, seja obtida com cursos pós-graduados de mestrado, elevando assim o patamar de qualificação dos docentes" (PINTASSILGO; MOGARRO; HENRIQUES, 2010, p. 35). 
As áreas do conhecimento foram agrupadas para efeitos de recrutamento e, através de decreto, o governo estabelece quais são as especialidades do mestrado que devem ser cursadas e os critérios mínimos de formação na área de docência. Diferente do Brasil, não é necessário ter uma determinada graduação para ensinar uma determinada disciplina, mas ter cursado a carga de créditos da área específica em qualquer que seja o curso superior e que permite o ingresso ao Mestrado em Ensino específico.

A seguir, apresenta-se uma tabela que relaciona os Mestrados, créditos e grupos de recrutamento para as áreas que integram o ensino secundário:

\section{FIGURA 7 - REQUISITOS DE FORMAÇÃO DOS PROFESSORES DO ENSINO SECUNDÁRIO}

\begin{tabular}{|c|c|c|c|}
\hline \multirow{2}{*}{$\begin{array}{l}\text { Especialidade do grau de mestre } \\
\text { Ensino de Português no } 3 .^{\circ} \text { Ciclo } \\
\text { do Ensino Básico e no Ensino } \\
\text { Secundário. }\end{array}$} & \multirow{2}{*}{$\begin{array}{l}\begin{array}{l}\text { Requisitos mínimos para } \\
\text { ingresso no ciclo de estudos } \\
\text { conducente ao grau de mestre }\end{array} \\
120 \text { créditos em Português. }\end{array}$} & \multicolumn{2}{|c|}{$\begin{array}{l}\text { Grupos de } \\
\text { recrutamento }\end{array}$} \\
\hline & & 300 & Português \\
\hline \multirow{2}{*}{$\begin{array}{l}\text { Ensino de Português no } 3 .^{\circ} \text { Ciclo } \\
\text { do Ensino Básico e no Ensino } \\
\text { Secundário e de Latim no Ensino } \\
\text { Secundário. }\end{array}$} & \multirow{2}{*}{$\begin{array}{l}80 \text { a } 100 \text { créditos em Português. } \\
40 \text { a } 60 \text { créditos em Latim e } \\
\text { Estudos Clássicos. }\end{array}$} & 300 & Português \\
\hline & & 310 & $\begin{array}{l}\text { Latim e } \\
\text { Grego }\end{array}$ \\
\hline \multirow{2}{*}{$\begin{array}{l}\text { Ensino de Português e de Alemão } \\
\text { no } 3{ }^{\circ} \text { Ciclo do Ensino Básico e } \\
\text { no Ensino Secundário. }\end{array}$} & \multirow{2}{*}{$\begin{array}{l}80 \text { a } 100 \text { créditos em Português. } \\
60 \text { a } 80 \text { créditos em Alemão. }\end{array}$} & 300 & Português \\
\hline & & 340 & Alemão \\
\hline \multirow{2}{*}{$\begin{array}{l}\text { Ensino de Português e de } \\
\text { Espanhol no } 3 .^{\circ} \text { Ciclo do Ensino } \\
\text { Básico e no Ensino Secundário. }\end{array}$} & \multirow{2}{*}{$\begin{array}{l}80 \text { a } 100 \text { créditos em Português. } \\
60 \text { a } 80 \text { créditos em Espanhol. }\end{array}$} & 300 & Português \\
\hline & & 350 & Espanhol \\
\hline \multirow{2}{*}{$\begin{array}{l}\text { Ensino de Português e de Francês } \\
\text { no } 3 .^{\circ} \text { Ciclo do Ensino Básico e } \\
\text { no Ensino Secundário. }\end{array}$} & \multirow{2}{*}{$\begin{array}{l}80 \text { a } 100 \text { créditos em Português. } \\
60 \text { a } 80 \text { créditos em Francês. }\end{array}$} & 300 & Português \\
\hline & & 320 & Francês \\
\hline \multirow{2}{*}{$\begin{array}{l}\text { Ensino de Português e de Inglês } \\
\text { no } 3 .^{\circ} \text { Ciclo do Ensino Básico e } \\
\text { no Ensino Secundário }\end{array}$} & \multirow{2}{*}{$\begin{array}{l}80 \text { a } 100 \text { créditos em Português. } \\
60 \text { a } 80 \text { créditos em Inglês. }\end{array}$} & 300 & Português \\
\hline & & 330 & Inglês \\
\hline $\begin{array}{l}\text { Ensino de Inglês no } 3 .^{\circ} \text { ciclo } \\
\text { do Ensino Básico e no Ensino } \\
\text { Secundário. }\end{array}$ & 120 créditos em Inglês. & 330 & Inglês \\
\hline \multirow{2}{*}{$\begin{array}{l}\text { Ensino de Inglês e de Alemão no } \\
3 .^{\circ} \text { Ciclo do Ensino Básico e no } \\
\text { Ensino Secundário. }\end{array}$} & \multirow{2}{*}{$\begin{array}{l}80 \text { a } 100 \text { créditos em Inglês. } 60 \text { a } \\
80 \text { créditos em Alemão. }\end{array}$} & 330 & Inglês \\
\hline & & 340 & Alemão \\
\hline
\end{tabular}

(continua) 


\begin{tabular}{|c|c|c|c|}
\hline \multirow{2}{*}{$\begin{array}{l}\text { Ensino de Inglês e de Espanhol no } \\
3 .^{\circ} \text { Ciclo do Ensino Básico e no } \\
\text { Ensino Secundário. }\end{array}$} & \multirow{2}{*}{$\begin{array}{l}80 \text { a } 100 \text { créditos em Inglês. } 60 \text { a } \\
80 \text { créditos em Espanhol }\end{array}$} & 330 & Inglês \\
\hline & & 350 & Espanhol \\
\hline \multirow{2}{*}{$\begin{array}{l}\text { Ensino de Inglês e de Francês no } \\
\text { 3. }{ }^{\circ} \text { Ciclo do Ensino Básico e no } \\
\text { Ensino Secundário. }\end{array}$} & \multirow{2}{*}{$\begin{array}{l}80 \text { a } 100 \text { créditos em Inglês. } 60 \text { a } \\
80 \text { créditos em Francês. }\end{array}$} & 330 & Inglês \\
\hline & & 320 & Francês \\
\hline $\begin{array}{l}\text { Ensino de Filosofia no Ensino } \\
\text { Secundário. }\end{array}$ & 120 créditos em Filosofia. & 410 & Filosofia \\
\hline $\begin{array}{l}\text { Ensino de História no } 3 .^{\circ} \text { Ciclo } \\
\text { do Ensino Básico e no Ensino } \\
\text { Secundário. }\end{array}$ & 120 créditos em História. & 400 & História \\
\hline $\begin{array}{l}\text { Ensino de Geografia no } 3 .^{\circ} \text { Ciclo } \\
\text { do Ensino Básico e no Ensino } \\
\text { Secundário. }\end{array}$ & 120 créditos em Geografia. & 420 & Geografia \\
\hline $\begin{array}{l}\text { Ensino de Economia e de } \\
\text { Contabilidade. }\end{array}$ & $\begin{array}{l}120 \text { créditos no conjunto das duas } \\
\text { áreas disciplinares e nenhuma } \\
\text { com menos de } 50 \text { créditos. }\end{array}$ & 430 & $\begin{array}{l}\text { Economia e } \\
\text { Contabilidade }\end{array}$ \\
\hline $\begin{array}{l}\text { Ensino de Matemática no } 3 .^{\circ} \\
\text { Ciclo do Ensino Básico e no } \\
\text { Secundário. }\end{array}$ & 120 créditos em Matemática. & 500 & Matemática \\
\hline $\begin{array}{l}\text { Ensino de Física e de Química no } \\
\text { 3. }{ }^{\circ} \text { Ciclo do Ensino Básico e no } \\
\text { Ensino Secundário. }\end{array}$ & $\begin{array}{l}120 \text { créditos no conjunto das duas } \\
\text { áreas disciplinares e nenhuma } \\
\text { com menos de } 50 \text { créditos. }\end{array}$ & 510 & $\begin{array}{l}\text { Física e } \\
\text { Química }\end{array}$ \\
\hline $\begin{array}{l}\text { Ensino de Biologia e Geologia no } \\
\text { 3. }{ }^{\circ} \text { Ciclo do Ensino Básico e no } \\
\text { Ensino Secundário. }\end{array}$ & $\begin{array}{l}120 \text { créditos no conjunto das duas } \\
\text { áreas disciplinares e nenhuma } \\
\text { com menos de } 50 \text { créditos. }\end{array}$ & 520 & $\begin{array}{l}\text { Biologia e } \\
\text { Geologia }\end{array}$ \\
\hline $\begin{array}{l}\text { Ensino de Energias, de } \\
\text { Eletrônica e de Automação. }\end{array}$ & $\begin{array}{l}150 \text { créditos no conjunto das três } \\
\text { áreas disciplinares e nenhuma } \\
\text { com menos de } 40 \text { créditos. }\end{array}$ & 540 & Eletrotecnia \\
\hline Ensino de Informática. & 120 créditos em Informática. & 550 & Informática \\
\hline $\begin{array}{l}\text { Ensino de Ciências } \\
\text { Agropecuárias }\end{array}$ & $\begin{array}{l}120 \text { créditos em Ciências } \\
\text { Agropecuárias }\end{array}$ & 560 & $\begin{array}{l}\text { Ciências } \\
\text { Agropecuárias }\end{array}$ \\
\hline $\begin{array}{l}\text { Ensino de Artes Visuais no 3. } \\
\text { Ciclo do Ensino Básico e no } \\
\text { Ensino Secundário. }\end{array}$ & 120 créditos em Artes Visuais. & 600 & Artes Visuais \\
\hline \multirow{2}{*}{$\begin{array}{l}\text { Ensino de Educação Física nos } \\
\text { Ensinos Básico e Secundário. }\end{array}$} & \multirow{2}{*}{$\begin{array}{l}120 \text { créditos em Educação Física } \\
\text { e Desporto. }\end{array}$} & 260 & $\begin{array}{l}\text { Educação } \\
\text { Física }\end{array}$ \\
\hline & & 620 & $\begin{array}{l}\text { Educação } \\
\text { Física }\end{array}$ \\
\hline
\end{tabular}

FONTE: Decreto-Lei n. ${ }^{0}$ 79/2014 de 14 de maio de 2014 e Declaração de Retificação n. ${ }^{\circ}$ 32/2014 de 27 de junho de 2014 (PORTUGAL, 2014a, 2014b). 
Esta tabela levanta diversas dúvidas: as disciplinas não listadas na tabela, por exemplo, mecânica, turismo ou àquelas ligadas a saúde, estariam dentro das áreas criadas? Como se organizam os mestrados destinados à formação dos professores dos conteúdos técnicos específicos?

A partir desta informação, buscou-se investigar nas destacadas universidades de Portugal $^{4}$ a oferta de Mestrados em Ensino. Dentre todos os mestrados ofertados, foi possível encontrar uma única oferta de Mestrado em Ensino de Economia e Contabilidade, ofertado pela Universidade de Lisboa. Os mestrados em Ensino de Ciências Agropecuárias e de Ensino de Energias, de Eletrônica e de Automação não foram encontrados nas informações prestadas por estas universidades, o que faz pensar sobre qual seria o requisito que estaria sendo praticado para ingresso na carreira docente se não há oferta dos cursos que habilitariam?

No Brasil, a LDB, desde 1996, previa que todo o docente para atuar na educação básica deveria possuir formação pedagógica que lhe habilitasse. Assim, a educação profissional que está integrada ao ensino médio, como etapa da educação básica, deveria ter professores com formação. Ocorre que os concursos públicos raramente praticavam tal solicitação, já que não havia, de forma regular, oferta de cursos de formação pedagógica com tal finalidade e a legislação previa um prazo para que se tornasse obrigatório. Isso fez com que ao longo dos anos o contingente de professores sem habilitação fosse se ampliando e a solução parecia distante, quando em final de 2016 houve uma reforma na legislação, permitindo que para a educação profissional o professor pudesse ter notório saber, ao invés da formação anteriormente prevista (BRASIL, 2017a).

Não se sabe exatamente precisar o que a legislação pretende ou pretendia com tal abertura, mas fica evidente que ao flexibilizar os requisitos de ingresso destes professores para a docência, a obrigatoriedade da formação pedagógica, para os diversos profissionais formados em suas áreas específicas, tornou-se frágil e, talvez, difícil de ser sustentada pelas instituições que já não estavam praticando essa solicitação em seus concursos de contratação docente anteriormente.

A profissionalização do professor que atua na educação profissional é um campo em disputa. No ano de 2015, foram publicadas as Diretrizes Curriculares Nacionais para a formação inicial em nível superior dos professores (BRASIL, 2015), carregando as marcas de sua história:

4 Universidade de Lisboa, Universidade Nova de Lisboa, Instituto Politécnico de Lisboa, Universidade do Minho, Universidade de Coimbra, Universidade de Aveiro e Universidade do Porto. 
Art. 14. Os cursos de formação pedagógica para graduados não licenciados, de caráter emergencial e provisório, ofertados a portadores de diplomas de curso superior formados em cursos relacionados à habilitação pretendida com sólida base de conhecimentos na área estudada, devem ter carga horária mínima variável de 1.000 (mil) a 1.400 (mil e quatrocentas) horas de efetivo trabalho acadêmico, dependendo da equivalência entre o curso de origem e a formação pedagógica pretendida (BRASIL, 2015).

Ou seja, embora apresente avanço de, pela primeira vez, regular a formação de professores para atuar na Educação Profissional e Tecnológica, estabelecendo a formação pedagógica para graduados não-licenciados como o itinerário destinado a isso, permanece em seu cerne as palavras "de caráter emergencial e provisório", apontando que na visão legal, o ponto permanece sem uma solução considerada adequada.

Estas palavras vêm acompanhando o campo da formação de professores para EPT e têm pautado as diversas pesquisas que vêm sendo realizadas e que concluem pela necessidade de uma Agenda, na qual "a luta pelo posicionamento do MEC sobre a obrigatoriedade da licenciatura para a docência na EPT" seja uma das pautas essências, bem como "o comprometimento efetivo das instituições de EP com a formação continuada de seus docentes (OLIVEIRA, 2013, p. 99).

Nem mesmo esta resolução havia sido implantada em todo o país, em 2019, houve a aprovação das novas Diretrizes Curriculares Nacionais para a Formação Inicial de Professores para a Educação Básica e Base Nacional Comum para a Formação Inicial de Professores da Educação Básica (BNC-Formação) através da Resolução 22 do Conselho Nacional de Educação. (BRASIL,2019). Nesta nova legislação, embora as palavras emergenciais e provisória tenham desaparecido, ocorre uma diminuição nas horas destinadas aos estudos teóricos, demonstrando uma concepção de formação com hegemonia da prática, já que $53 \%$ da carga-horária curricular está concentrada neste grupo (GRUPO II), conforme pode ser observado a seguir:

\subsubsection{Da Formação Pedagógica}

No caso de graduados não licenciados, a habilitação para o magistério se dará no curso destinado à Formação Pedagógica, que deve ser realizado com carga horária básica de 760 (setecentas e sessenta) horas, com a forma e a seguinte distribuição:

- Grupo I: 360 (trezentas e sessenta) horas para o desenvolvimento das competências profissionais integradas às três dimensões constantes da BNC-Formação, proposta por este Parecer. 
- Grupo II: 400 (quatrocentas) horas para a prática pedagógica na área ou no componente curricular (BRASIL, 2019).

Pode-se perceber que no Brasil a questão legal ainda se encontra em forte disputa, não obtendo consenso, tal qual parece ocorrer em Portugal. Em relação a realidade das escolas, no entanto, a situação de ter professores com formação pedagógica para as disciplinas técnicas parece ser semelhante nos dois países e faz pensar sobre qual a visão de docência praticada nesta modalidade de ensino e sobre como estes docentes desenvolvem os saberes para o ofício no qual atuam. A seguir, apresenta-se uma síntese das análises empreendidas aqui nas considerações finais.

\section{Considerações finais}

"Os estudos comparados não podem realizar-se numa perspectiva meramente descritiva, necessitando de uma elaboração conceptual que dê um sentido à inter-relação e à comparação de diferentes realidades" (POPKEWITZ; PEREYRA, 1992, p. 13). Ainda assim, a descrição é parte importante à compreensão. Pode-se afirmar que sobre o tema Educação Profissional, localizou-se pouca produção que trate de perspectivas de organização, estruturação e docência, comparando distintas realidades nacionais, tendo destaque a obra de Pardal, Ventura e Dias (2005).

Apesar disso, as reformas recentemente implantadas no Brasil recorrem ao argumento de modelos internacionais de "sucesso" para se sustentar, o que torna importante trazer estudos comparados que possam problematizar estes discursos, contribuindo para a compreensão do local, a partir de um global (BRASIL, 2017a). Ignorar o contexto é o suficiente para tornar iguais coisas desiguais, e desiguais, as coisas iguais. (BOURDIEU; PASSERON, 1979). Por conseguinte, o primeiro movimento do estudo foi brevemente apresentar os contextos organizacionais da Educação Profissional, em nível de ensino secundário, em Portugal e no Brasil. A seguir, explorou-se a questão dos requisitos à docência para esta modalidade de ensino, em ambos os países.

Conclui-se que os modelos educativos de ambos os países têm algumas similaridades, mas se encontram em contextos de valorização bastante diferenciados, uma vez que Portugal está caminhando para a inserção majoritária de seus estudantes na Educação Profissional, enquanto que o Brasil, a partir da 
reforma, parece tomar o caminho de investir na flexibilização dos currículos de Ensino Médio, como resposta à problemática de "falta" de interesse pelos jovens nesta etapa educacional (BRASIL, 2017a).

Ainda, pode-se afirmar que o Brasil, que tinha investido em uma legislação que recorria à profissionalização docente para todos os professores que atuassem na Educação Básica, etapa na qual se encontra a Educação Profissional de nível médio, recua com a nova legislação, permitindo o notório saber. Portugal, apesar de ter uma legislação que obriga todos os docentes da Educação Profissional que atuam no secundário a terem Mestrado em Ensino em suas respectivas áreas, parece recorrer ao Decreto-Lei n. ${ }^{\circ} 132 / 2012$, de 27 de junho (PORTUGAL, 2012), para a contratação temporária de técnicos especializados que prestem serviço docente e de formação em áreas técnicas específicas e, neste caso, por não serem professores, mas formadores, não há o requisito de ter Mestrado em Ensino, mas de ser certificado pelos Centros de Formação Profissional, em cursos de aproximadamente 100 horas.

Neste sentido, poderia se pensar se isto não equivaleria ao notório saber, entendido aqui como o reconhecimento de saberes de profissionais altamente especializados em suas áreas e que, através de sua prática no mundo do trabalho, agregariam valor a formação em um determinado momento, com a diferença de que Portugal aponta para a formação desejada ao exercício da docência, mestrado em ensino, enquanto que o Brasil normatiza o que pode ser entendido como um recuo a profissionalização docente.

Cabe destacar ainda que o exercício da profissão docente na Educação Profissional requer mais do que somente os conhecimentos advindos do mundo do trabalho, requer conhecimentos oriundos das ciências da educação, assim como conhecimentos didático-pedagógicos necessários para a construção de prática docente dos conteúdos específicos.

Entende-se que a docência na Educação Profissional é tarefa complexa e que, em função disso, de difícil definição. Apesar disso, é fundamental que se afirme como uma profissão para a qual é necessária a formação adequada, perpassando assim pelo domínio de conteúdos específicos e pedagógicos, sem os quais o professor acaba por ser um reprodutor de livros ou aplicador de métodos didáticos prontos, o que esvazia a dimensão intelectual do ofício docente. É papel do Estado e das Instituições a garantia de espaços e tempos destinados à formação inicial e continuada dos professores, não devendo ser vista como tarefa individual, mas compromisso coletivo com a construção de uma educação de qualidade. 


\section{REFERÊNCIAS}

BOGDAN, Robert; BIKLEN, Sari Knopp. Investigação qualitativa em educação. Tradução de Maria João Alvarez, Sara Bahia dos Santos e Telmo Mourinho Baptista. Porto, Portugal: Porto Editora, 1994.

BOURDIEU, Pierre; PASSERON, Jean-Claude. A comparabilidade dos sistemas de ensino. In: DURAND, José Carlos Garcia (org.). Educação e hegemonia de classe: as funções ideológicas da escola. Rio de Janeiro: Zahar, 1979.

BRASIL. Lei no 9.394, de 20 de dezembro de 1996. Lei de Diretrizes e Bases da Educação Nacional. Brasília, DF: Presidência da República. Disponível em: http://www.planalto. gov.br/ccivil_03/Leis/L9394.htm. Acesso em: 20 jun. 2017.

BRASIL. Lei $n^{o} 13.415$, de 16 de fevereiro de 2017. Brasília, DF: Presidência da República, 2017a. Disponível em: http:/www.planalto.gov.br/ccivil_03/_ato20152018//2017/lei/113415.htm. Acesso em: 10 mar. 2020.

BRASIL. Ministério da Educação. Catálogo Nacional de Cursos Técnicos. Brasília, DF: Presidência da República, 2016. Disponível em: http://portal.mec.gov.br/index. php?option=com_docman\&view=download\&alias=41271-cnct-3-edicao-pdf\&category_ slug=maio-2016-pdf\&Itemid=30192. Acesso em: 20 jun. 2017.

BRASIL. Ministério da Educação. Censo Escolar da Educação Básica 2016. Notas Estatísticas. Instituto Nacional de Estudos e Pesquisas Educacionais Anísio Teixeira. Brasília, DF: Ministério da Educação, 2017b. Disponível em: http://download.inep.gov. br/educacao_basica/censo_escolar/notas_estatisticas/2017/notas_estatisticas_censo_ escolar_da_educacao_basica_2016.pdf. Acesso em: 20 jun. 2017.

BRASIL. Ministério da Educação. Resolução $C N E / C P n^{\circ} 2$ de $1^{\circ}$ de julho de 2015. Define as Diretrizes Curriculares Nacionais para a formação inicial em nível superior e para a formação continuada. Brasília, DF: Ministério da Educação, 2015. Disponível em: http://portal.mec.gov.br/docman/agosto-2017-pdf/70431-res-cne-cp-002-03072015-pdf/ file. Acesso em: 10 mar. 2020.

BRASIL. Ministério da Educação. Resolução $C N E / C P n^{\circ} 4$ de 17 de dezembro de 2018. Institui a Base Nacional Comum Curricular na Etapa do Ensino Médio. Brasília, DF: Ministério da Educação, 2018. Disponível em: http://portal.mec.gov.br/index. php?option=com_docman\&view=download\&alias=104101-rcp004-18\&category_ slug=dezembro-2018-pdf\&Itemid=30192. Acesso em: 10 mar. 2020.

BRASIL. Ministério da Educação. Resolução $C N E / C P n^{\circ} 22$ de 07 de novembro de 2019. Institui as Diretrizes Curriculares Nacionais para a Formação Inicial de Professores para a Educação Básica e Base Nacional Comum para a Formação Inicial de Professores da Educação Básica. Disponível em: http://portal.mec.gov.br/index.php?option=com_do cman\&view=download\&alias=133091-pcp022-19-3\&category_slug=dezembro-2019pdf\&Itemid=30192. Acesso em: 10 mar. 2020. 
MOURAZ, Ana; LEITE, Carlinda; FERNANDES, Preciosa. Formação Inicial de Professores em Portugal Decorrente do Processo de Bolonha: Uma Análise a Partir do "Olhar" de Professores e de Estudantes. Revista Portuguesa de Pedagogia, Coimbra, v. 46, n. 2, p. 189-209, 2012.

NÓVOA, António. Modelos de análise de educação comparada: o campo e o mapa. In: SOUZA, Donaldo Bello de; MARTÍNEZ, Silvia Alicia (org.). Educação Comparada: rotas de Além-mar. São Paulo: Editora Xamã, 2010.

OLIVEIRA, Maria Rita Neto Sales. A Pesquisa sobre a formação de professores para Educação Profissional. In: MOURA, Dante Henrique (org.). Produção de conhecimento, políticas públicas e formação docente em Educação Profissional. Campinas: Mercado das Letras, 2013.

PARDAL, Luís; VENTURA, Alexandre; DIAS, Carlos. Ensino Médio e Ensino Técnico no Brasil e em Portugal: raízes históricas e panorama atual. Campinas, SP: Autores Associados, 2005.

PEREIRA, Eva Wairos; TEIXEIRA, Zuleide Araújo. Reexaminando a educação Básica na LDB: ganhos e perdas após dezessete anos. In: BRZEZINSKI, Iria (org.). LDB/1996 Contemporânea: contradições, tensões, compromissos. São Paulo: Cortez, 2014.

PINTASSILGO, Joaquim; MOGARRO, Maria João; HENRIQUES, Raquel Pereira. $A$ formação de professores em Portugal. Lisboa, Portugal: Edições Colibri, 2010.

POPKEWITZ, Thomas; PEREYRA, Miguel. Práticas de reforma na formação de professores em oito países: esboço de uma problemática. In: NÓVOA, António; POPKEWITZ, Thomas S. (org.). Reformas educativas e formação de professores. Lisboa: Educa, 1992.

PORTUGAL. Agência Nacional para a Qualificação e o Ensino Profissional. Circular n. 1/ANQEP/2017. Lisboa: ANQEP, 2017. Disponível em: http://www.catalogo.anqep. gov.pt/boDocumentos/getDocumentos/558. Acesso em: 10 mar. 2020.

PORTUGAL. Ministério da Educação. Estatísticas do Ensino Secundário. Gabinete de Estatística e Planeamento da Educação. Lisboa, Portugal: Ministério da Educação, 2015. Disponível em: http://infoescolas.mec.pt/Secundario/\#.WTmL7Wjyu00. Acesso em: 31 mar. 2018.

PORTUGAL. Ministério da Educação. Estatísticas do Ensino Secundário. Gabinete de Estatística e Planeamento da Educação. Lisboa, Portugal: Ministério da Educação, 2018. Disponível em: https://www.dgeec.mec.pt/np4/96/. Acesso em: 31 mar. 2018.

PORTUGAL. Ministério da Educação. Educação em Números. Gabinete de Estatística e Planeamento da Educação. Lisboa, Portugal: Ministério da Educação, 2008. Disponível em: https://www.dgeec.mec.pt/np4/96/\%7B\$clientServletPath\%7D/?newsId=145\&file Name=educacao_numeros2008.pdf. Acesso em: 31 mar. 2018. 
PORTUGAL. Ministério da Educação. Lei de Bases do Sistema Educativo. Lei $n^{\circ}$ 49/2005 de 30 de Agosto de 2005. Lisboa, Portugal: Ministério da Educação, 2005. Disponível em: http://www3.uma.pt/nunosilvafraga/wp-content/uploads/2007/07/lei-de-bases-dosistema-educativo.pdf. Acesso em: 07 jun. 2017.

PORTUGAL. Ministérios da Educação e da Ciência, Tecnologia e Ensino Superior. Decreto-Lei n. ${ }^{\circ}$ 79/2014 de 14 de maio de 2014. Aprova o regime jurídico da habilitação profissional para a docência na educação pré-escolar e nos ensinos básico e secundário. Diário da República. Lisboa, PT 14 maio 2014. Lisboa, Portugal: Ministério da Educação e da Ciência, Tecnologia e Ensino Superior, 2014a. Disponível em: https://dre.pt/ application/dir/pdf1sdip/2014/05/09200/0281902828.pdf. Acesso em: 14 jun. 2017.

PORTUGAL. Ministérios da Educação e da Ciência, Tecnologia e Ensino Superior. Declaração de Retificação n. ${ }^{\circ}$ 32/2014 de 27 de Junho de 2014. Retifica o Decreto-Lei n. ${ }^{\circ} 79 / 2014$ de 14 de Maio. Diário da República, 1. ${ }^{\text {a }}$ série, N. ${ }^{\circ}$ 122, 27 de junho de 2014. Lisboa, Portugal: Ministério da Educação e da Ciência, Tecnologia e Ensino Superior, 2014b. Disponível em: https://dre.pt/application/dir/pdf1sdip/2014/06/12200/0352103523. pdf. Acesso em: 14 jun. 2017.

PORTUGAL. Ministérios da Educação e da Ciência, Tecnologia e Ensino Superior. Decreto-Lei n. ${ }^{\circ}$ 132/2012, de 27 de junho de 2012. Estabelece o novo regime de recrutamento e mobilidade do pessoal docente dos ensinos básico e secundário e de formadores e técnicos especializados. Diário da República, n. ${ }^{\circ}$ 123/2012, Série I de 2012-06-27. Lisboa, Portugal: Ministério da Educação e da Ciência, Tecnologia e Ensino Superior, 2012. Disponível em: https://dre.pt/web/guest/legislacaoconsolidada/-/lc/106490508/201704030659/exportPdf/normal/1/cacheLevelPage? LegislacaoConsolidada_WAR_drefrontofficeportlet_rp=indice. Acesso em: 07 dez. 2017.

TORRES, Haroldo da Gama et al. O Que Pensam os Jovens de Baixa Renda sobre a Escola. Projeto de pesquisa desenvolvido pelo CEBRAP com o apoio da Fundação Victor Civita. Relatório final. São Paulo: Fundação Vítor Cívita, 2013. Disponível em: http://www.fvc.org.br/estudos-e-pesquisas/2012/pdf/relatorio_jovens_pensam_escola. pdf. Acesso em: 06 jun. 2017.

Texto recebido em 11/02/2020.

Texto aprovado em 20/10/2020. 